\title{
Homozygous Null Genotype at Glutathione $S$-transferase $M 1$ Locus as a Risk Factor for Oral Squamous Cell Carcinoma in Indian Tobacco Users
}

\author{
Nilabja Sikdar*, Sila Datta+, Badal Dey*, Ranjan Rashmi Paul ${ }^{+}$, \\ Chinmay Kumar Panda" and Bidyut Roy* \\ *Human Genetics Unit, Biological Sciences Division, Indian Statistical Institute, 203 B. T. \\ Road, Kolkata 700 108, West Bengal, India \\ +Department of Oral Pathology and Microbiology, R. Ahmed Dental College and Hospital, \\ Kolkata 700 014, West Bengal, India \\ \#Department of Oncogene Regulation, Chittaranjan National Cancer Institute, 37 S. P. \\ Mukherjee Road, Kolkata 700 026, West Bengal, India
}

\begin{abstract}
KEYWORDS Indian population; tobacco smoking/chewing; oral SCC; GSTM1; GSTT1; CYP1A1; CYP2E1; genetic polymorphism
\end{abstract}

\begin{abstract}
Inter-individual differences in sensitivity to chemical carcinogens may contribute to differences in susceptibility to human cancer subsequent to environmental exposures. It has been reported that polymorphisms in glutathione S-transferase (GST) and cytochrome P-450 oxidase $(C Y P)$ genes are associated with increased risk of tobacco-related cancers in different ethnic populations. In this study, we investigated polymorphisms in GSTM1, GSTT1, CYP1A1 and CYP2E1 genes in 80 oral squamous cell carcinoma (SCC) patients and 67 controls from one Indian population. Prevalence of the GSTM1 homozygous null genotype was 39 in 80 patients (49\%) compared to 18 in 67 controls (27\%) [age and sex adjusted $\mathrm{OR}=1.8,95 \% \mathrm{CI}=1.0-3.6$ ]. Analyses of data on polymorphisms in GSTT1, CYP1A1 and CYP2E1 did not reveal significant differences in distribution of genotypes between patient and control groups. Our results confirm that GSTM1 homozygous null genotype adds to the risk of oral cancer development among tobacco users. But low sample size limited the power to estimate tobacco dose-genotype interactions.
\end{abstract}

\section{INTRODUCTION}

Incidence of head and neck cancer ranks first in males and third in females among all cancers in India (Parkin et al. 1997; ICMR 1992) whereas it ranks fifth globally (Parkin et al. 1993). Epidemiologically it has been associated with frequent use of tobacco smoking and chewing with or without betel quid (product of chewing betel leaf along with areca nut and lime) in India as well as South-East Asian countries (ICMR 1992; Ko et al. 1995). Tobacco smoking and alcohol con-sumption have been identified as the main risk factors for oral cancer in Western population (La Vecchia et al. 1997). Polycyclic aromatic hydro-carbons (PAHs), aldehydes and nitrosamines are thought to be carcinogenic components present in tobacco smoking. But

*Address for Correpondence: Dr. Bidyut Roy, Human Genetics Unit, Indian Statistical Institute, 203 B. T. Road, Kolkata 700 108, West Bengal, India

Telephone: (033) 2575-3213/3212

Fax: (033) 2577-3049,

E-mail: broy@isical.ac.in chewing of tobacco with betel quid increases the concentrations of carcinogenic tobaccospecific nitrosamines and reactive oxygen species in mouth (Nair et al. 1992). It is now accepted that carcinogenic risks from exposure to exogenous chemicals depend not only on the intrinsic nature and dose of each chemical but also on inter-individual variability in sensitivity to the carcinogens.

Most pro-carcinogens require metabolic activation by Phase I enzymes (e.g. cytochrome P450 oxidase (CYP) 1A1, 2E1) to act as carcinogens but detoxification of the same by Phase II metabolic enzymes (e.g. glutathione Stransferase $(G S T) M 1, T 1)$ are also maintained by the body to protect itself against the ill effects of carcinogens. CYPIAl and CYP2El are considered to play important roles in the activation of PAHs and nitrosamines, respectively (Kadlubar and Hammons, 1987). The polymorphic MspI site in CYPIAl gene, at the $264^{\text {th }}$ base downstream from additional poly (A) signal in the 3'-flanking region, has been shown to be associated with susceptibility to lung and oral 
SCC (Le Marchand et al. 1998; Sato et al. 1999; Tanimoto et al. 1999). But lack of association has also been reported in different populations (Matthias et al. 1998; Katoh et al. 1999). Polymorphism at Pst I site, in the transcription regulation region of $C Y P 2 E 1$, can modulate gene expression. The rare/variant allele increased expression of chloramphenicol acetyltransferase gene in HepG2 cell line in vitro assay (Hayashi et al. 1991). The association between variant genotype at this site of CYP2E1 gene and prevalence of oral cancer has also been reported (Hung et al. 1997; Tan et al. 2000; Liu et al. 2001).

The known substrates of GSTM1 include metabolically generated epoxide intermediates of benzo-a-pyrene (BP) and other PAHs, whereas those of GSTT1 include alkyl halides found in tobacco smoke. GSTM1 and GSTT1 enzymes are known to catalyze detoxification of reactive oxygen species formed in oral cavity during chewing of tobacco with betel nut and lime (Nair et al. 1999). Homozygous GSTM1 null genotype has been associated with higher risk of laryngeal, lung, bladder and colon cancers (Hayashi et al. 1992; Lafuente et al. 1993; Chenevix-Trench et al. 1995; Katoh et al. 1996; Jourenkova-Mironova et al. 1998; Cheng et al. 1999). Some studies reported positive association between the GSTM1 null genotype and high risk of oral cancer among Japanese (Katoh et al. 1999; Sato et al. 1999) but others failed to observe this association in same population (Tanimoto et al. 1999). Similarly, studies on Caucasians also reported both the presence and absence of association (Trizana et al. 1995; Park et al. 1997). Homozygous null genotype at GSTT1 has been reported to be associated with increased risk of brain and colorectal cancer (Elexpuru-Camiruaga et al. 1995; Deakin et al. 1996). Most association studies between genetic polymorphism and tobacco use have focussed on tobacco-smoking related cancer risk, but only a few studies have reported tobacco chewing-related oral cancer (Ko et al. 1995; Soni et al. 1995; Kietthubthew et al. 2001; Sreelekha et al 2001;). Oral cancer attributable to tobacco chewing and smoking is a significant public health burden in India and South-East Asia. Studies, on different Indian populations, reported both presence and absence of increased risk of oral cancer due to polymorphisms in GST and CYP genes (Sreelekha et al 2001; Buch et al 2002; Sikdar et al 2004). So, it is important to conduct this study in different ethnic populations to arrive at a meaningful conclusion. Here we report oral cancer risk among tobacco chewers and smokers in relation to polymorphisms in CYPIAl, CYP2E1, GSTM1 and GSTT1 genes in an East Indian population.

\section{MATERIALSANDMETHODS}

Study Populations: All patient and control individuals belonged to same ethnic population (called "Bengalee") and were living in Kolkata, previously known as Calcutta, a big city on Eastern part of India. Information on tobacco smoking, chewing and keeping in-mouth, alcohol consumption, duration of habits, age and sex of all individuals were recorded during an interview by Dental Doctor at the time of first visit. Most of the patients and controls belonged to lowincome group (family income $<100$ US $\$$ per month) and this is one of the reasons for which they visited Government hospital for treatment. Both patients and controls had occupations in diverse areas such as agriculture, industry, car driving, private sector office, small business etc. Most of the females were housewives and doing only household jobs. Written consents were obtained from all individuals before collection of blood and tissue samples as required in this study.

Patients: Individuals attended Chittaranjan National Cancer Hospital (a tertiary referral center, $\mathrm{n}=26$ ) and Dr. R. Ahmed Dental College and Hospital (a secondary referral center, $n=54$ ), both located in Kolkata, for treatment of oral lesions during the years 1998-1999 and were enrolled as cases in this study with written consent. Biopsy materials from oral lesions of the patients were histologically examined for SCC. All patients $(n=80)$ had at least one kind of tobacco habit.

Controls: Individuals attended Nilratan Sircar Medical College and Hospital (a general hospital) in Kolkata, India, for treatment of diseases such as cough \& cold, indigestion, tuberculosis, gynecological problem during the year 1998; but without any lesion in oral cavity and were enrolled as controls in this study $(n=40)$. Individuals suffering (or having history of suffering) from lung, colon, gastric, bladder cancers etc. which are known to be influenced by tobacco habits, were excluded from this study at the time of enrollment. Some healthy individuals $(n=27)$, without any lesion in oral cavity, also volunteered to become controls in 
this study. All individuals $(n=67)$ who were aged $>40$ years and had habits of tobacco smoking or/ and chewing or/and keeping in-mouth but without any oral lesions, were recruited as controls.

Tobacco and Alcohol Habits: Three ways of tobacco use, namely smoking, keeping/dipping in mouth for 2-4 hr and chewing for 1-2 hr, were observed in patients and controls. Tobacco was smoked either in the form of cigarette or bidi (about 2-3-inch long tobacco stick that contained tobacco flakes packed in a Temburni leaf wrapper). Tobacco dippers kept tobacco, mixed with lime in between lower lip and teeth. Chewers used tobacco in the form of betel quid that comprises leaf of betel vine (Piper betle $L$ ) wrapped around areca or betel nut (nut of Areca catechu $L$ ), slaked lime, catcheu (extract of Acacia catechu L) and tobacco. Individuals in study population were divided into two habits groups: tobacco "chewers/keepers" and "smokers". About $85 \%$ of smokers had habits of both cigarettes and bidis, so bidi and cigarettes smokers were not analyzed separately. In patient group, only few $(<5 \%)$ had occasional alcohol drinking history and none of the controls had alcohol-drinking habit. So, alcohol consumption was not considered in statistical analysis. Duration of tobacco habits ranged 5-25 yr. in patients and controls.

DNA Isolation and Genotyping: Genomic DNA was isolated from venous blood of patient and control individuals by proteinase- $\mathrm{K}$ treatment and salt extraction procedure (Miller et al. 1988).

Homozygous null genotypes at GSTMI and GSTT1 were determined using a multiplex hotstart polymerase chain reaction (PCR) procedure, for simultaneous amplification of both genes and an internal control, in GeneAmp PCR system 2400 (PE Biosystems, USA). The primer sequences and PCR conditions were similar as described by Nair et al. (1999), except 1 U of Platinum DNA Taq polymerase (Gibco BRL, Life Technologies, Rockville, MD) was used in these reactions. Amplified PCR products were electrophoresed in $2 \%$ agarose gel and stained with ethidium bromide. Homozygous GSTM1 and GSTT1 null genotypes were evidenced by the absence of 215 bp and 480 bp fragments in the PCR products, respectively, along with the presence of an internal control band of $350 \mathrm{bp}$ albumin fragment.

Genotype identification of the CYPIA 1 was carried out by PCR amplification of DNA samples followed by digestion with MspI to detect substitution of $C T G G$ allele (lack of $M s p$ I recognition site i.e. - site) by $C C G G$ allele (presence of $M s p I$ recognition site i.e. + site) at the $M s p I$ polymorphic site (Sato et al. 1999). The digested products were electrophoresed in $1.5 \%$ agarose and stained with ethidium bromide to count the genotypes +/+, +/-, and -/- of the samples.

Similarly $C Y P 2 E 1$ genotypes of DNA samples were detected by PCR amplification followed by digestion with Pst I enzyme (Kato et al. 1992). The digested PCR products were electrophoresed in $2 \%$ agarose gel and stained with ethidium bromide to count the genotypes $(+/+$, $+/-,-/-)$ of the samples based on the presence (+) or absence (-) of enzyme recognition site.

PCR Product Sequencing: Few PCR products (5\%), from all loci, were sequenced (ABI prism 3100, Applied Biosystem) to confirm the genotypes which were determined by PCR and PCRRFLP methods.

Statistical Analysis: Age and sex adjusted risk of oral cancer was calculated as odds ratios (ORs) and 95\% confidence interval (CIs) for genotypes in all patients by multiple logistic regression analysis using SPSS statistical package. Chi-square test with Yates' correction was used for comparison of proportions. Due to low sample size, they were not stratified on the basis of chewing and smoking habits and doses for analysis.

\section{RESULT}

A total of 80 oral cancer patients and 67 controls were included in this study and the patients were almost similar in mean age with respect to controls $(52.8 \pm 12.4$ and $55.3 \pm 11.7 \mathrm{yr}$, respectively). The smokers comprised 27 patients and 16 controls and chewers/keepers were 53 in patient and 51 in control groups, respectively (Table 1). Major tumor sites were buccal mucosa (30\%) followed by tongue $(24 \%)$, cheek $(10 \%)$ and floor of the mouth (5\%). Remaining patients were affected at one or two of the following sites e.g. lip, tonsil, larynx, mandible, palate and alveolar mucosa.

Genotypes (5\%) determined by sequencing method was identical to those done by PCR or PCR-RFLP methods at all loci (data not shown). So, remaining genotypes were determined by PCR or PCR-RFLP methods. Distribution of GSTM1 homozygous null genotype in patients 
$(\mathrm{n}=39,49 \%)$ was significantly higher $(\mathrm{OR}=1.8$, 95\% CI=1.0-3.6) than controls $(\mathrm{n}=18,27 \%)$ but that of GSTT1 was similar in both groups (Table 2). Frequency of individuals having homozygous null genotypes in both GSTM1 and GSTT1 was greater among patients $(n=6,8 \%)$ compared to controls $(\mathrm{n}=1,1 \%)$ thus suggesting higher risk of oral cancer in individuals with homozygous null genotypes in both genes. We also compared frequencies of GSTM1 and GSTT1 homozygous null genotypes among patients and controls on the basis of kind of tobacco habits (i.e. smoking or chewing/keeping) but no significant differences were observed (data not shown). More sample size may be needed to determine the independent effect of smoking or chewing/keeping on the risk of oral cancer among GSTM1 and GSTT1 homozygous null individuals.

Frequency of CYP1Al variant (+/+) genotype

Table 1: Description of patients and controls

\begin{tabular}{lrr}
\hline $\begin{array}{l}\text { Demography and } \\
\text { tobacco habits }\end{array}$ & $\begin{array}{r}\text { Patients } \\
(N=80) \\
n(\%)\end{array}$ & $\begin{array}{r}\text { Controls } \\
(N=67) \\
n(\%)\end{array}$ \\
\hline Male & $67(84)$ & $41(61)$ \\
Female & $13(16)$ & $26(39)$ \\
Age $( \pm$ S.D.) yr. & $52.8( \pm 12.4)$ & $55.3( \pm 11.7)$ \\
$\begin{array}{l}\text { Tobacco smoking } \\
\text { Tobacco chewing or/and } \\
\text { keeping in mouth }\end{array}$ & $27(34)$ & $16(24)$ \\
& $53(66)$ & $51(76)$
\end{tabular}

at MspI site in patients $(\mathrm{n}=8,10 \%)$ was not significantly different than controls $(n=5,7 \%)$. Frequencies of combined variant and heterozygous CYP1Al genotypes were also not significantly different among patients and controls (data not shown and Table 3). The CYP2E1 variant $(+/+)$ genotype at Pst I site was absent among patients and controls. But the frequency of heterozygous (+/-) CYP2E1 genotype in patients $(n=4,5 \%)$ was not significantly different than controls $(\mathrm{n}=1,1 \%)$.

\section{DISCUSSION}

Majority of the patients (66\%) and controls $(76 \%)$ had the habit of using smokeless tobacco either in the form of 'keeping in mouth' or chewing or both. The remaining patients (34\%) and controls $(24 \%)$ had tobacco smoking habit (Table 1). Since epidemiological studies had already established that tobacco smoking as well as chewing are causative agents for oral cancer in Indian and Taiwanese populations (IARC 1986; Sankaranarayanan et al. 1990) so we tried to recruit controls who were matched in tobacco habits of patients. Duration and dosage of tobacco habits were not considered for any analyses because of low sample size. In this study, ratios of males to females were more among

Table 2: Distribution of GSTMI and GSTT1 homozygous null genotypes in patients and controls

\begin{tabular}{|c|c|c|c|c|c|c|}
\hline \multirow{2}{*}{$\begin{array}{l}\text { Subjects } \\
(N)\end{array}$} & \multicolumn{2}{|c|}{ GSTM1 null } & \multicolumn{2}{|c|}{ GSTT1 null } & \multicolumn{2}{|c|}{ Null at both genes } \\
\hline & $N(\%)$ & $\begin{array}{r}O R, * \\
(95 \% C I)\end{array}$ & $N(\%)$ & $\begin{array}{r}\text { OR, } \\
(95 \% \text { CI })\end{array}$ & $N(\%)$ & $\begin{array}{r}O R \\
(95 \% C I)\end{array}$ \\
\hline Patients (80) & $39(49)$ & \multirow[t]{2}{*}{$\begin{array}{r}1.8 \\
(1.0-3.6)\end{array}$} & $11(14)$ & \multirow[t]{2}{*}{$\begin{array}{r}1.2 \\
(0.5-2.9)\end{array}$} & $6(8)$ & \multirow[t]{2}{*}{$\begin{array}{r}4.7 \\
(0.5-40.9)\end{array}$} \\
\hline Controls (67) & $18(27)$ & & $9(13)$ & & $1(1)$ & \\
\hline
\end{tabular}

*; age and sex adjusted; $\mathrm{p}=0.01$

Table 3: Distribution of CYP1A1 and CYP2E1 genotypes in patients and controls

\begin{tabular}{|c|c|c|c|c|c|c|c|c|}
\hline \multirow[t]{2}{*}{ Subjects } & \multicolumn{4}{|c|}{ * CYP1A1 genotypes at Msp I site } & \multicolumn{4}{|c|}{${ }^{*}$ CYP2E1 genotypes at PstI site } \\
\hline & $\begin{array}{r}+/+ \\
N(\%)\end{array}$ & $\begin{array}{r}+/- \\
N(\%)\end{array}$ & $N(\%)$ & $\begin{array}{c}O R \\
95 \% C I\end{array}$ & $\begin{array}{r}+/+ \\
N(\%)\end{array}$ & $\begin{array}{c}+/- \\
N(\%)\end{array}$ & $N(\%)$ & $\begin{array}{r}O R, \\
95 \% C I\end{array}$ \\
\hline $\begin{array}{l}\text { Patients } \\
(\mathrm{N}=79 / 78)\end{array}$ & $8(10)$ & $40(51)$ & $31(39)$ & $\begin{array}{r}1.3 \\
0.3-6.0\end{array}$ & $0(0)$ & $4(5)$ & $74(95)$ & $\begin{array}{r}2.4, \\
0.4-48\end{array}$ \\
\hline $\begin{array}{l}\text { Controls } \\
(\mathrm{N}=67)\end{array}$ & $5(7)$ & $33(50)$ & $29(43)$ & & $0(0)$ & $1(1)$ & $66(99)$ & \\
\hline
\end{tabular}

Few patients could not be typed. +, - ; alleles represent presence and absence of MspI and PstI enzyme recognition sites in CYP1A1 and CYP2E1 genes, respectively.

*; Variant homozygotes (+/+) in CYP1A1 gene and heterozygotes (+/-) in CYP2E1 gene were compared for age and sex adjusted OR and 95\% CI 
patients (5.1: 1) than controls (1.6:1). Females in India are traditionally not tobacco smokers but both males and females use smokeless tobacco. This possibly explains the higher prevalence of oral cancer among males than females in India, which was reflected in Table 1 and also known from other epidemiological data (ICMR 1992).

Frequencies of GSTMI and GSTT1 homozygous null genotypes vary widely in global different populations. GSTM1 homozygous null genotype ranged from $22-35 \%$ in Africans, 38$67 \%$ in Caucasians and $33-63 \%$ in East Asian populations. GSTT1 homozygous null genotype ranged from 10-18\% in Caucasians and was 58\% in Chinese populations (Lee et al. 1995; Nelson et al. 1995; Rebbeck 1997). The frequencies of homozygous null genotypes in 'Asian Indians' living in Los Angeles and Malaysia have been reported to be $33-36 \%$ (GSTMI) and $16 \%$ (GSTT1), respectively (Lin et al. 1994; Lee et al. 1995; Zhao et al. 1995). In a study (Roy et al. 2001), we observed wide variation in the frequencies of homozygous null genotypes in different ethnic Indian populations from Eastern and Northern parts of India (frequency ranges were $20-79 \%$ in GSTM1 and 3-39\% in GSTT1 genes, respectively). In a case-control study on oral leukoplakia from an Indian population, Nair et al (1999) reported that frequencies of GSTM1 and GSTT1 homozygous null genotypes were $17 \%$ and $22 \%$, respectively, in control individuals who were chosen from a city (Bombay) located on Western part of India. In another study, Sreelekha et al. (2001) reported frequencies of GSTM1 and GSTT1 homozygous null genotypes as $33 \%$ and $8 \%$, respectively, in their control population from South India. But prevalence of GSTM1 and GSTT1 homozygous null genotypes were $27 \%$ and $13 \%$, respectively, in our control individuals who were from a city (Kolkata) located on Eastern part of India. These differences in the frequencies of GSTM1 and GSTT1 homozygous null genotypes in populations from three geographical regions suggest genomic diversity in different ethnic populations of India.

The patient and control individuals of this study were similar in ethnicity (called Bengalee) and nutrition (as they belonged to low income group). Occupationally neither the patients nor the controls were exposed to any toxic chemicals. The effects, if any, of confounding factors such as ethnicity, diet and occupation would be similar in patients and controls. In this study, $49 \%$ of the patients had GSTM1 homozygous null genotype compared to $27 \%$ in controls $(p=0.01)$ whereas frequencies of GSTT1 homozygous null genotype were similar in patients $(14 \%)$ and controls $(13 \%)$. So, the significant difference in the frequencies of GSTM1 homozygous null genotype in patients and controls, observed in this study, may be attributed as real rather than artifact (Table 2). Since GSTM1 could detoxify activated tobacco carcinogens such as PAHs and nitrosamines, so the patients lacking this gene, i.e. this enzyme, became susceptible to tobacco smoking and chewing. This study also supports the observation on positive association between presence of GSTM1 homozygous null genotype and risk of oral cancer reported in a West-Indian population (Buch et al. 2002). Some studies have reported presence of positive association between GSTM1 homozygous null genotype and high risk of oral cancer in Japanese population (Katoh et al. 1999; Sato et al. 1999) but others have failed to observe this association in same population (Hori et al. 1997; Tanimoto et al. 1999). Similarly, studies on Caucasian population also reported both presence and absence of this association (Trizana et al. 1995; Park et al. 1997). Jourenkova-Mironova et al (1999) and Hung et al (1997) reported presence of association between GSTT1 homozygous null genotype and increased oral cancer risk in Caucasian and Chinese patients respectively which was not observed in this study. Lack of positive association between GSTT1 homozygous null genotype and increased risk of oral cancer were also reported in Indian populations (Sreelekha et al. 2001; Buch et al. 2002). The reasons for this discrepancy in findings between Indian and other populations might be due to differences in ethnicity, nature of the tobacco habit and small sample size.

Frequency of variant homozygote at $M s p \mathrm{I}$ site of CYPIAl gene (i.e. +/+ genotype) was $7 \%$ in this control population (Table 3) which had been reported to be $8 \%$ and less than $1 \%$ in Japanese and Caucasian populations, respectively (Cascorbi et al. 1996; Tanimoto et al. 1999). Frequency of rare homozygote at PstI site in $C Y P 2 E 1$ gene (i.e. +/+ genotype) was $0 \%$ in this study (Table 3 ) which had been reported to be $3 \%$ and less than $1 \%$ in Japanese and Caucasian populations, respectively (Kato et al. 1992). Absence of rare genotype at Pst I site in CYP2E1 gene, in all individuals $(n=145)$ of this study, raises 
the possibility that a selection pressure might have acted on this gene. Although CYPIAl and CYP2El are important for activation for PAHs and nitrosamines, the frequencies of rare CYPIAl and heterozygous $C Y P 2 E 1$ genotypes did not differ significantly between patients and controls in this study (Table-3). Reports on Japanese, Caucasian and Chinese populations described association between rare homozygote at $M s p \mathrm{I}$ site in CYP1Al and increased risk of oral SCC (Sato et al. 1999; Tanimoto et al. 1999). Again, lack of association was also observed in Japanese (Katoh et al. 1999) as well as Caucasian population (Matthias et al. 1998). But, our results indicated that polymorphisms at $M s p \mathrm{I}$ site of CYP1Al and PstI site of CYP2El genes did not modulate risk of oral SCC in this population. Lack of association between CYP2E1 genotype and increased risk of oral cancer is not in consistence with the reports on Caucasians and Chinese (Chenevix-Trench et al. 1995; JourenkovaMironova et al. 1998). The CYPIA1 and CYP2E1 genes possess other polymorphic sites that are known to modify enzyme activity in vivo (Tsutsumi et al. 1994; Sreelekha et al. 2001), so it will be worthwhile to look into those polymorphic sites for association study. Differences in the frequencies of combined genotypes, such as (homozygous GSTM1 null + variant CYP1A1) and (homozygous GSTMI null + heterozygous CYP2E1), were not significant between patient and control groups (data not shown) which were not in consistence with other reports (Sato et al. 1999; Sreelekha et al. 2001; Tanimoto et al. 1999). In conclusion, this study indicated that individuals with GSTM1 null genotypes had high risk of oral SCC but further study with more samples is needed to substantiate this observation.

\section{ACKNOWLEDGEMENT}

This work was supported by a grant from Department of Science and Technology, Government of India, 1999-2002. We are grateful to Dr. A. Mahmud, Mr. G. Sabbir and Mr. M. Chakraborty for sample collection and technical assistance during this work. We thank Prof. P. P. Majumder for suggestions during statistical analysis.

\section{REFERENCES}

Buch SC, Notani PN, Bhisey RA 2002. Polymorphism at GSTM1, GSTM3 and GSTT1 gene loci and susceptibility to oral cancer in an Indian population. Carcinogenesis, 23: 803-807.

Cascorbi I, Brockmoller J, Roots I 1996. A C4887A polymorphism in exon 7 of human CYP1A1: population frequency, mutation linkages, and impact on lung cancer susceptibility. Cancer Res, 56: 49654969 .

Chenevix-Trench G, Young J, Coggan M, Board P 1995. Glutathione $-S$ - transferase $M 1$ and $T 1$ polymorphisms: Susceptibility to colon cancer and age of onset. Carcinogenesis, 16: 1655-1657.

Cheng L, Sturgls EM, Eicher SA, Char D, Spitz MR, Wei Q 1999. Glutathione-S-transferase polymorphisms and risk of squamous cell carcinoma of the head and neck. Int J Cancer, 84: 220-224.

Deakin M, Elder J, Hendrickse C, Peckham D, Baldwin D, Pantin C, Wild N, Leopard P, Bell DA, Jones P, Duncan H, Brannigan K, Alldersea J, Fryer AA, Strange RC 1996. Glutathione S-transferase GSTT1 genotypes and susceptibility to cancer: studies of interaction with GSTM1 in lung, oral, gastric and colorectal cancers. Carcinogenesis, 17: 881-884.

Elexpuru-Camiruaga J, Buxton N, Kandula V, Dias PS, Campbell D, et al. 1995. Susceptibility to astrocytoma and meningioma: influence of allelism at glutathione $S$-transferase (GSTT1 and GSTM1) and cytochrome P-450 (CYP2DO) loci. Cancer Res, 55: 4237-4239.

Hayashi S, Watanabe J, Kawajiri K 1991. Genetic polymorphisms in the 5 '-flanking region change transcriptional regulation of the human cytochrome P450IIE1 gene. J Biochem (Tokyo), 110: 559565.

Hayashi S, Watanabe J, Kawajiri K 1992. High susceptibility to lung cancer analyzed in terms of combined genotypes of $\mathrm{P} 4501 \mathrm{~A} 1$ and $\mathrm{Mu}$ class glutathione $S$-transferase genes. Jpn J Cancer Res, 83: $866-870$

Hori H, Kawano T, Endo M, Yuasa Y 1997. Genetic polymorphisms of tobacco and alcohol-related metabolizing enzymes and human esophageal squamous cell carcinoma susceptibility. J Clin Gastroenterol, 25: 568-575.

Hung HC, Chuang J, Chien YC, Chern, HD, Chiang CP, Kuo YS, Hilde A, Chen CJ 1997. Genetic polymorphisms of CYP2E1, GSTM1, and GSTT1; environmental factors and risk of oral cancer. Cancer Epidemiol Biomark Prev, 11: 901-905.

IARC 1986. Betel-quid and area-nut chewing. International agency for research on cancer, Lyon, France. Monographs, Vol. 37: 142-291.

ICMR, Indian Council of Medical Research 1992. National Cancer Registry Programme: Biennial Report 1988- 1989. New Delhi, India: ICMR.

Jourenkova-Mironova N, Reinikainen M, Bouchardy C, Dayer P, Benhamou S, Hirvonen A 1998. Larynx cancer risk in relation to glutathione $S$-transferase $M 1$ and $T 1$ genotypes and tobacco smoking. Cancer Epidemiol. Biomark. \& Prev, 7: 19-23.

Jourenkova-Mironova N, Voho A, Bouchardy C, Wikman H, Dayer P, Benhamou S, Hirvonen A. 1999. Glutathione S-transferase GSTM1, GSTM3, GSTP1 and GSTT1 genotypes and the risk of smokingrelated oral and pharyngeal cancers. Int J Cancer, 81: $44-48$ 
Kadlubar FF, Hammons GJ. 1987. Role of cytochrome P-450 in metabolism of chemical carcinogens. In: F. P. Guengerich (Ed): Mammalian Cytochromes P-450, Vol. 2, pp. 81-130, Boca Raton FL: CRC Press.

Kato S, Shields GP, Caporaso EN, Hoover NR, Trump FB, Sugimura H, Weston A, Harris CC 1992. Cytochrome P450IIE1 genetic polymorphisms, racial variation and lung cancer risk. Cancer Res, 52: 6712-6715.

Katoh T, Nagata N, Kuroda Y, Itoh H, Kawahara A, Kuroki N, Ookuma R, Bell DA 1996. Glutathione$S$ - transferase M1 (GSTM1) and T1 (GSTT1) genetic polymorphism and susceptibility to gastric and colorectal adenocarcinoma. Carcinogenesis, 17: $1855-1859$.

Katoh T, Kaneko S, Kohshi K, Munaka M, Kitagawa K, Kunigata N, Ikemura K, Kawamoto T. 1999. Genetic polymorphisms of tobacco-and alcohol-related metabolizing enzymes and oral cavity cancer. Int $J$ Cancer, 83: 606-609.

Kietthubthew S, Sriplung H, Au WW 2001. Genetic and environmental interactions on oral cancer in Southern Thailand. Environ Mol Mutagen, 37: 111116.

Ko CY, Huang LY, Lee HC, Chen JM, Lin ML, Tsai CC 1995. Betel quid chewing, cigarette smoking and alcohol consumption related to oral cancer in Taiwan. J Oral Pathol Med, 24: 450-453.

La Vecchia C, Tavani A, Francesch S, Levi F, Corrao G, Negr E 1997. Epidemiology and prevention of oral cancer. Oral Oncol, 33: 302-312

Lafuente A, Pujol F, Carretero P, Villa JP, Cuchi A 1993. Human glutathione S-transferase mu (GST mu) deficiency as a marker for the susceptibility to bladder and larynx cancer among smokers. Cancer Lett, 68: 49-54.

Lee EJ, Wong JY, Yeoh PN, Gong NH 1995. Glutathione S-transferase-theta (GSTT1) genetic polymorphism among Chinese, Malays and Indians in Singapore. Pharmacogenetics, 5: 332-334.

Lin HJ, Han CY, Bernstein DA, Hsiao W, Lin BK, Hardy S 1994. Ethnic distribution of the glutathione transferase mu 1-1 (GSTM1) null genotype in 1473 individuals and application to bladder cancer susceptibility. Carcinogenesis, 15: 1077-1081.

Liu S, Park JY, Schantz SP, Stern JC, Lazarus P 2001. Elucidation of CYP2E1 5' regulatory RsaI/PstI allelic variants and their role in risk for oral cancer. Oral Oncology, 37: 437-445.

Le Marchand L, Sivaraman L, Pierce L, Seifried A, Lum A, Wilkens RL, Au FA 1998. Association of CYP1A1, GSTM1, and CYP2E1 polymorphisms with lung cancer suggests cell type specificities to tobacco carcinogens. Cancer Res, 58: 4858-4863.

Matthias C, Bockmuhl U, Jahnke V, Jones PW, Hayes JD, Alldersa J, Gilford J, Bailey L, Bath J, Worrall SF, Hand P, Frayer AA, Strange RC 1998. Polymorphism in cytochrome P450 CYP2D6, $C Y P 1 A 1, C Y P 2 E 1$ and glutathione $S$-transferase GSTM1, GSTM3, GSTT1 and susceptibility to tobacco-related cancers: studies in upper aerodigestive tract cancers. Pharmacogenetics, 8: 91-100.

Miller SA, Dykes DD, Polesky HK 1988. A simple salting out procedure for extracting DNA from human nucleated cells. Nuc Acids Res, 16: 1215.

Nair UJ, Obe G, Friesen M, Goldberg MT, Bartsch H 1992. Role of lime in the generation of reactive oxygen species from betel-quid ingredients. Environ Health Perspect, 98: 203-205.

Nair UJ, Nair J, Mathew B, Bartsch H 1999. Glutathione $S$-transferase M1 and T1 null genotypes as risk factors for oral leukoplakia in ethnic Indian betel quid/ tobacco chewers. Carcinogenesis, 20: 743748

Nelson HH, Wiencke JK, Christiani DC, Cheng TJ, Zuo Z-F, Schwartz BS, Lee, B.K, Spitz MR, Wang M, Xu XP, Kelsey KT 1995. Ethnic differences in the prevalence of the homozygous deleted genotype of glutathione-S-transferase theta. Carcinogenesis, 16: $1243-1245$.

Park JY, Muscat JE, Ren Q, Schantz SP, Harwick RD, Stern JC, Pike V, Richie JP, Lazarus P 1997. CYP1A1 and GSTM1 polymorphisms and oral cancer risk. Cancer Epidemiol. Biomarkers Prev, 6: 791-797.

Parkin DM, Pisani P, Ferlay J 1993. Estimates of the worldwide incidence of eighteen major cancers in 1985. Int J Cancer, 54: 594-606

Parkin DM, Whelan SL, Ferlay J, Raymond LA, Woung J 1997. Cancer Incidence in Five Continents vol. VII. IARC Scientific Publications, No. 143, IARC, Lyon.

Rebbeck TR 1997. Molecular epidemiology of the human glutathione $-S$-transferase genotypes GSTM1 and GSTT1 in cancer susceptibility. Cancer Epidemiol Biomarkers Prev, 6: 733-743.

Roy B, Majumder PP, Dey B, Chakraborty M, Banerjee S, Roy M, Mukherjee N, Sil S 2001. Ethnic differences in distributions of GSTM1 and GSTT1 'null' genotypes in India. Human Biology, 73: 443450.

Sankaranarayanan R, Duffy SW, Padmakumary G, Day NE, Nair MK 1990. Risk factors for buccal and labial mucosa in Kerala, Southern India. J Epidemiol Commun Health, 44: 286-292.

Sato M, Sato T, Izumo T, Amagasa T 1999. Genetic polymorphism of drug-metabolizing enzymes and susceptibility to oral cancer. Carcinogenesis, 20: 1927-1931.

Sikdar N, Paul RR, Roy B 2004. Glutathione $S$-transferase M3 (A/A) genotype as a risk factor for oral cancer and leukoplakia among Indian tobacco smokers. Int J Cancer, 109: 95-101.

Soni MG, Krishna TP, Krishnaswamy K 1995. Human leukocyte glutathione $S$ - transferase isozyme (class $\mathrm{mu}$ ) and susceptibility to smoking related cancers. $J$ Toxicol Environ Health, 46: 1- 8.

Sreelekha TT, Ramdas K, Pandey M, Thomas G, Nalinakumari KR, Pillai MR 2001. Genetic polymorphism of CYP1A1, GSTM1 and GSTT1 gene in Indian oral cancer. Oral Oncol, 37: 593-598.

Tan W, Song N, Wang G-Q et al. 2000. Impact of genetic polymorphisms in cytochrome $P 4502 E 1$ and glutathione $S$-transferases $M 1, T 1$ and $P 1$ on susceptibility to esophageal cancer among high-risk individuals in China. Cancer Epidemiol Biomark Prev, 9: 551-556.

Tanimoto K, Hayashi S, Yoshiga K, Ichikawa T 1999. Polymorphism of the CYP1A1 and GSTM1 gene involved in oral squamous cell carcinoma in 
association with a cigarette dose. Oral Oncol, 35: 191-196.

Trizana Z, Clayman GL, Spitz MR, Briggs KL, Goepfert H 1995. Glutathione- $S$-transferase genotypes as risk factors for head and neck cancer. Am J Surg, 170: 499-501.

Tsutsumi M, Wang JS, Takase S. et al. 1994. Hepatic messenger RNA contents of cytochrome P450 2E1 in patients with different $P-4502 E 1$ genotypes. Alcohol, 29 (Suppl. 1): 29-32.

Zhao B, Lee EJ, Wong JY, Yeoh PN, Gong NH 1995. Frequency of mutant CYP1A1, NAT2 and GSTM1 alleles in normal Indians and Malays. Pharmacogenetics, 5: 275-280. 